\title{
Use of Miniplates in Parasymphysis Fractures: A Survey Conducted among Oral and Maxillofacial Surgeons of India
}

\author{
Harish Saluja, Vipin Dehane, Yogesh Kini, Uma Mahindra
}

\begin{abstract}
Aim: Aim of the study was to find out the number of miniplates used by Indian oral and maxillofacial surgeons for parasymphysis fractures.
\end{abstract}

Study design: A survey was done among oral and maxillofacial surgeons of India at the 34th annual meeting of Association of Oral and Maxillofacial Surgeons of India. Four questions were given to each individual to find out their opinion regarding use of miniplates in parasymphysis fractures.

Results: Eighty-eight percent of Indian surgeons were in favor of using intraoperative or postoperative intermaxillary fixation. Thirty-eight percent responded in favor of using single miniplate for parasymphysis fracture instead of using two miniplates. 54\% maxillofacial surgeons use various modifications depending on different conditions. $42 \%$ of maxillofacial surgeons accepted that lower arch bar can be used as a tension band.

Conclusion: Use of miniplates for the treatment of parasymphysis fracture varies from center to center and from surgeon to surgeon. Though miniplates are best used following Champy's principle, still many surgeons use single miniplate. Arch bars placed for intermaxillary fixation can be used as a tension band, again eliminating the need for upper plate.

Keywords: Miniplates, Parasymphysis, Fracture, Tension band.

How to cite this article: Saluja H, Dehane V, Kini Y, Mahindra $U$. Use of Miniplates in Parasymphysis Fractures: A Survey Conducted among Oral and Maxillofacial Surgeons of India. Int $\mathrm{J}$ Head and Neck Surg 2012;3(1):8-10.

Source of support: Nil

Conflict of interest: None declared

\section{INTRODUCTION}

Miniplates are placed according to Champy's principle. Champy et al refined the work of Michelet et al after carefully considering the biomechanics of mandible and have described the osteosynthesis line for placing the miniplates in the mandible. In the mandible, a line drawn at the base of the alveolar process corresponds to the line of tension and monocortical plates and screws can be fixed along this line. In the parasymphysis region, another line is drawn near the lower border to neutralize the tension forces, as torsional forces in the parasymphysis region are very high. ${ }^{1,2}$ The principle of osteosynthesis according to Champy is to reestablish the mechanical qualities of the mandible, hence he advised to use of two miniplates in anterior region. ${ }^{1}$ One at the inferior border and second $5 \mathrm{~mm}$ above the lower plate. Champy did not advice use of intraoperative or postoperative intermaxillary fixation, but many authors feel the need of intraoperative or small period of postoperative intermaxillary fixation. Most surgeons who treat mandibular fractures with miniplate osteosynthesis technique still use IMF as a method of fracture reduction, in belief that this is essential to achieve a normal occlusion or recommend postoperative IMF for a small period. ${ }^{3,4}$ So, if routinely arch bars are placed for intermaxillary fixation, then lower arch bar can be used as a tension band and eliminate the need of upper (tension) plate. Some surgeons think that application of arch bar to the teeth may prohibit the rotational force. ${ }^{5}$ Some in vitro studies had shown that the amount of force in the symphysis area is same as that of mandibular body area so symphysis/parasymphysis fractures can be managed by single plates like that of body fracture. ${ }^{6,7}$ Even many authors had used various modifications for parasymphysis fractures instead of using two miniplates. ${ }^{8,9}$ So, the treatment of parasymphysis fracture using miniplates varies from surgeon to surgeon, center to center. Keeping these facts in mind a study was done among Indian oral and maxillofacial surgeons to find out whether we really follow Champy while using miniplates for parasymphysis fractures.

\section{Study Design}

The present survey was done among oral and maxillofacial surgeons of India at the 34th annual meeting of Association of Oral and Maxillofacial Surgeons of India (AOMSI) held at Coimbatore, Tamil Nadu (India) from 1st December 2010 to 4th December 2010. Survey was conducted to find out different treatment plans followed by Indian oral and maxillofacial surgeons for parasymphysis fractures while using miniplates. A questionnaire consisting of four questions were given to each individual to find out their opinion. The aim of the study was to find out the number of miniplates used for parasymphysis fractures.

Two hundred oral and maxillofacial surgeons were given a questionnaire and after response to questionnaire the forms were taken back. The questions asked were as follows:

1. Whether you use arch bars for IMF?

2. Whether you feel need of intraoperative/postoperative IMF?

3. How many plates do you use for parasymphysis fractures?

4. Can arch bar be used as a tension band eliminating the need of upper plate in parasymphysis fractures? 


\section{RESULTS}

In the survey conducted among 200 maxillofacial surgeons of India, 90\% regularly uses arch bars for intermaxillary fixation (Fig. 1). Eighty-eight percent of Indian surgeons were in favor of using intraoperative or postoperative intermaxillary fixation (Fig. 2). Thirty-eight percent responded in favor of using single miniplate for parasymphysis fracture (Fig. 3). Various modifications were used by different surgeons depending on different conditions especially when fracture line runs closer to mental foramina. Fifty-four percent maxillofacial surgeons use these

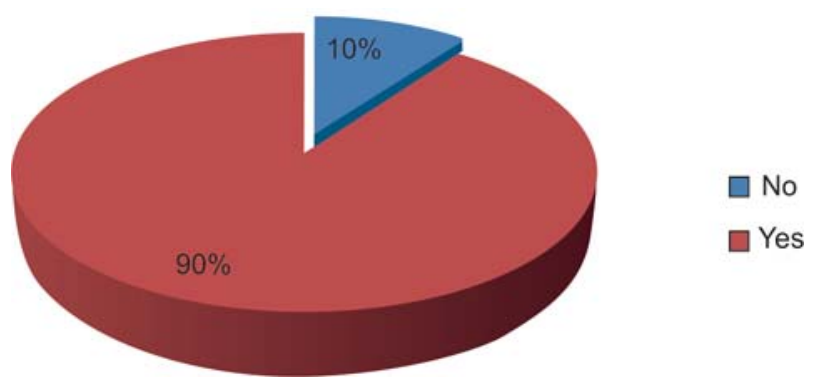

Fig. 1: Arch bar for IMF

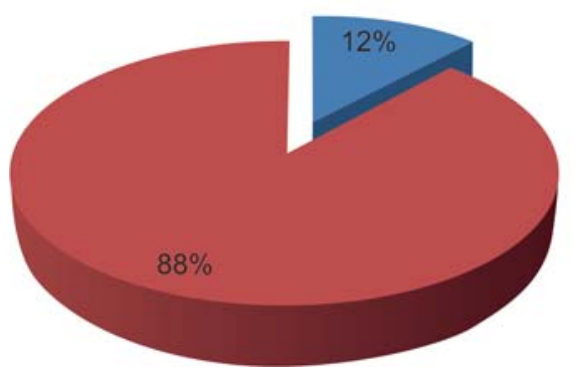

Fig. 2: Intraoperative/postoperative IMF

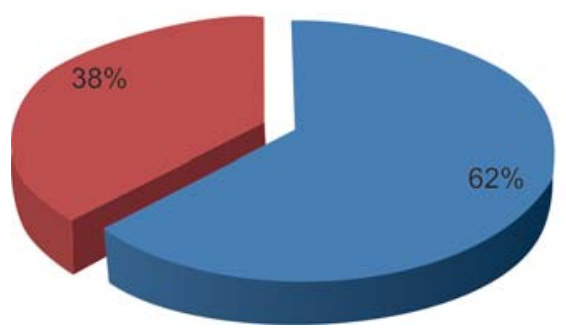

$\square$ Two miniplates $\square$ Single miniplate

Fig. 3: Plates use for parasymphysis fracture

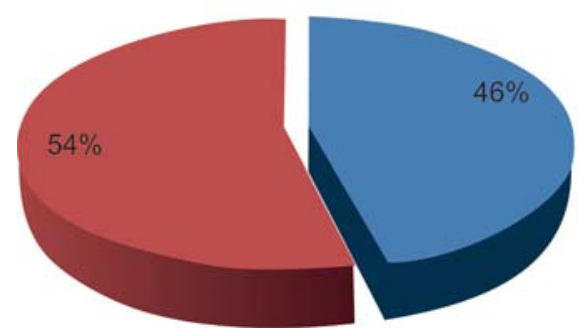

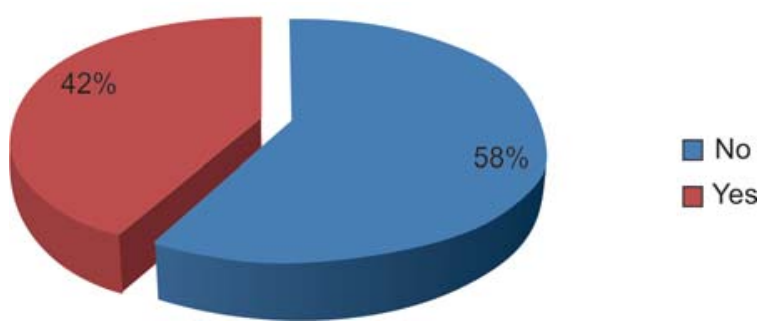

Fig. 5: Lower arch bar placed for intra/postoperative IMF used as a tension band

modifications (Fig. 4). Forty-two percent of maxillofacial surgeons accepted that lower arch bar can be used as a tension band and can eliminate the need for upper plate (Fig. 5).

\section{DISCUSSION}

Miniplates placed according to Champy's ideal lines should be placed within $10 \mathrm{~mm}$ of the superior border. But in the anterior part of the mandible, in front of premolar, torsional movements were more and were higher when they were near to the mandibular symphysis. A strong solid plate could be placed on the lower border; however, the risk of adaptation of the cortical plate to the shape of the plate is present. So, anterior to the mental foramina, additional torsional forces were opposed by putting another plate 4 to $5 \mathrm{~mm}$ below the subapical plate. ${ }^{1}$ These two plates counteracted the torsional as well the compressive forces. But in many in vitro three-dimensional studies of loads across the fracture site, authors found high torsion movements for symphysis fracture. According to them, the anterior body and canine fracture have similar maximum torsion movements. ${ }^{6,7}$ These values indicate that for a symphyseal fracture as well as for the body fracture, treatment with one bone plate should be sufficient.

Intraoperatively, most surgeons use intermaxillary fixation for fixation of fracture segments with miniplates, so preoperatively or intraoperatively arch bars are placed. Many authors have also suggested a small period postoperative intermaxillary fixation with the use of miniplates, again for which arch bars were needed. ${ }^{3,4}$ Many authors faced problem in restoring exact maxillomandibular occlusion without interdental fixation. ${ }^{10}$ Even many authors concluded that in case of comminuted fracture plating alone was not sufficient. But Champy did not advice intermaxillary fixation intra- or postoperatively. According to them, there is no need for intermaxillary fixation when one is going for open reduction, but practically most of the surgeons require intermaxillary fixation either intraoperatively or postoperatively for short period. So, the treatment plan for parasymphysis fractures varies a lot among various oral and maxillofacial surgeons. In our study, 
also $88 \%$ of Indian oral and maxillofacial surgeons believe in intraoperative or postoperative intermaxillary fixation.

In a study done by L Rix, a modification was used for parasymphysis fractures which are in close proximity to the mental foramen to avoid trauma to the nerve. ${ }^{9}$ Instead of customary two plates, only one plate was placed above the foramen and supplemented with loop wiring which included two or more teeth on either side of fracture line and their results were significant even with the use of this modification. In a study by KU Feller et al they used combination of miniplate and microplate for osteosynthesis of parasymphysis fracture because of limited space available in mental foramen and apical region. ${ }^{8}$ The results suggested that treatment of fractures in the interforaminal region with a combination of microplate and miniplate will be stable enough for early mobilization. In present study also, large number of surgeons were in the favor of using various modifications for parasymphysis fracture depending on various conditions like use of supplemented loop wiring, use of microplate instead of upper miniplate, etc.

Many studies showed that tensile forces exist at the superior border of mandible during function, so there must be some method of preventing distraction of the alveolar border to achieve uniform compression across the length of fracture. ${ }^{1,2}$ This brought about the tension band concept which can be in the form of a small miniplate at superior border or in the form of various arch bars at the alveolar segment. In mandible, a line drawn at the base of the alveolar process corresponds to the line of tension and monocortical plates and screws can be fixed along this line. In the parasymphysis region, another line is drawn near the lower border to neutralize the tension forces, as torsional forces in the parasymphysis region are very high. Champy had used upper plate as tension band but in our study $42 \%$ of surgeons think lower arch bar can be used as a tension band and eliminate the need of upper plate.

In two in vitro three-dimensional studies of loads across the fracture site, authors found high torsion movements for symphysis fracture. According to them, the anterior body and canine fracture have similar maximum torsion movements. ${ }^{6,7}$ These values indicate that for a symphyseal fracture as well as for the body fracture, treatment with one bone plate should be sufficient. In a study, done by Bolourian R et al single miniplate was used for mandibular fractures along with 2 weeks of maxillomandibular fixation. ${ }^{3}$ In our study group, also $38 \%$ of surgeons were in favor of using single miniplate in parasymphysis fracture.

\section{CONCLUSION}

This survey among Indian oral and maxillofacial surgeons had made us to conclude that use of miniplates for the treatment of parasymphysis fracture varies from center to center and from surgeon to surgeon. Though miniplates are best used following Champy's principle, still many surgeons use single miniplate and were satisfied with their results. Even many modifications can be used depending on different conditions. Arch bars placed can be use for intermaxillary fixation and can also act as tension band, again eliminating the need for upper plate.

\section{REFERENCES}

1. Champy M, Lodde JP, Schmitt R. Mandibular osteosynthesis by a miniature screwed plates via a buccal approach. J Maillofac Surg 1978;6:14-21.

2. Jones KJ, Sickels van EJ. Rigid fixation: A review of concepts and treatment of fractures. Oral Surg Oral Med Oral Pathol 1988;65:13-18.

3. Bolurian R, Lazow S, Berger J. Transoral $2.0 \mathrm{~mm}$ miniplate fixation of mandibular fractures plus 2 weeks maxillomandibular fixation: A prospective study. J Oral Maxillofac Surg 2002;60:167-70.

4. Al-Belasy Fouad A. A short period of maxillomadibular fixation for treatment of fractures of the mandibular tooth-bearing area. J Oral Maxillofac Surg 2005;63:953-56.

5. Ellis E, Ghali GE. Lag screw fixation of anterior mandibular fractures. J Oral Maxillofac Surg 1991;49:13-21.

6. Tams J, Van Loon JP, Rozema FR, Otten E, Bos RRM. A threedimensional study of loads across the fracture for different fracture sites of the mandible. Br J Oral Maxillofac Surg 1996;34:400-05.

7. Tams J, Van Loon JP, Rozema FR, Otten E, Bos RRM. A threedimensional study of bending and torsion movements for different fracture sites in the mandible: An in vitro study. Int $\mathrm{J}$ Oral Maxillofac Surg 1997;26:383-88.

8. Feller KU, Rechter G, Schneider M, Eckelt U. Combination of microplate and miniplate for osteosynthesis of mandibular fracture: An experimental study. Int J Oral Maxillofac Surg 2002;31:78-83.

9. Rix L, Stevenson ARL, Moorthy AP. An analysis of 80 cases of mandibular fractures treated with miniplates osteosynthesis. Int J Oral Maxillofac Surg 1991;20:337-41.

10. Fordyce AM, Lalani Z, Songra AK, Hildreth AJ, Carton ATM, Hawkesford JE. Intermaxillary fixation is not necessary to reduce mandibular fractures. Br J Oral Maxillofac Surg 1999;37: 52-57.

\section{ABOUT THE AUTHORS}

\section{Harish Saluja}

Assistant Professor, Department of Oral and Maxillofacial Surgery Rural Dental College, Loni, Maharashtra, India

\section{Vipin Dehane (Corresponding Author)}

Postgraduate Student, Department of Oral and Maxillofacial Surgery, Rural Dental College, Loni, Maharashtra, India, e-mail: vipindehane@gmail.com

\section{Yogesh Kini}

Professor, Department of Oral and Maxillofacial Surgery, Rural Dental College, Loni, Maharashtra, India

\section{Uma Mahindra}

Professor and Head, Department of Oral and Maxillofacial Surgery Rural Dental College, Loni, Maharashtra, India 